\title{
A case report on and chronic calcific pancreatitis primary systemic amyloidosis with symptomatic gastric involvement
}

\author{
Kumar R ${ }^{1}$, Chakraborthy SR ${ }^{2}$, Bandopadhyay $A^{3}$, Pandit VK ${ }^{4}$, Bandi HK \\ ${ }^{1}$ Dr. Rajesh Kumar, Consultant Medicine, ${ }^{2}$ Dr. SR Chakraborthy, Head, Gastroenterology Division, ${ }^{3}$ Dr. A \\ Bandopadhyay, Senior Consultant, Gastroenterology Division, ${ }^{4}$ Dr. VK Pandit, Senior Consultant, Gastroenterology \\ Division, ${ }^{5}$ Dr. HK Bandi, DNB Resident, Department of Medicine. All are affiliated with Bokaro General Hospital (DNB \\ teaching hospital, India.
}

Address for Correspondence: Email: Dr Rajesh Kumar, Email: drrajeshdr@yahoo.co.in

\begin{abstract}
Systemic amyloidosis is a disorder characterized by extracellular deposition ofamyloid in various organs and tissues including the gastrointestinal tract, kidney, heart, and liver.Gastric involvement occurs in $8-12 \%$ of patientswith only $1 \%$ being symptomatic. Histological involvement of gastrointestinal tract baring stomach is common but is often subclinical. Moreover pancreatic involvement is also rare. Herein we report a case of a 37-year old lady patient who presented with macroglossia, periorbital purpura, abdominal symptoms and on evaluation wasdiagnosedto be having systemic amyloidosis involving stomach and chronic calcific pancreatitis.
\end{abstract}

Keywords: Systemic amyloidosis, Calcific pancreatitis, Polypoidal gastric lesions, primary systemic amyloidosis with symptomatic gastric involvement.

\section{Introduction}

Amyloidosis is a multisystem disease caused by extracellular deposition offibrils composed of low molecular weight subunits of a variety of serum proteins. The accumulation of these protein subunits leads to a myriad of clinically relevant disorders. Amyloid proteins have pathognomonic apple-green birefringence in polarized light after Congo red staining [1]. Amyloidosis can be classified according to precursor protein which forms amyloid fibrils [2] such as primary amyloidosis (AL), which occurs in the setting of multiple myeloma or other plasma cell dyscrasias, secondary or reactive amyloidosis (AA) which occurs in chronicinflammatory diseases (such as rheumatoid arthritis) and with longterm hemodialysis, familial amyloidosis (ATTR) and senile systemic amyloidosis (SSA). $70 \%$ of cases of AL amyloidosisand55\% of AA amyloidosis involve gastrointestinal tract baring stomach (8\% - 12\%) and pancreas. [3] Amyloidosis involving the gastrointestinal tract can cause mild to severe bleeding [4]. Gastrointestinal bleeding in

Manuscript received: 09th Jan 2016,

Reviewed: 17th Jan 2016

Author Corrected: 27th Jan 2016,

Accepted for Publication: 08th Feb 2016 
amyloidosis results from local factors or coagulation factor deficiency [4]. Local mechanisms include wall ischemia, ulcer formation due to transmural amyloid in filtration, and mucosal fragility due to amyloid infiltration of blood vessels [5].

Amylodosis manifests as irregular and thickened gastrointestinal mucosaand may be confused with schirrous gastric carcinoma when found in the stomach. Exocrine pancreatic involvement in systemic amyloidosis is said to be very uncommon [6].

In 1993, Mayo clinic reviewed the clinical records of 769 patients withprimary systemic amyloidosis in different places of mayo clinic's and out of this 8 patient (1\%)was found to be associated with gastric amyloidosis [7].

\section{Case Report}

A 37 year old lady was admitted with complaints of loss of appetite, vomiting, pain abdomen in epigastric region with aggravation after food intake and progressive weight loss since past 6 months. She was on beta blockers for essential hypertension for 2 years.

On examination, macroglossia and periorbital purpura (Fig 1) were present with mild splenomegaly. Hemogram reports revealed mild anemia with normal total leucocyte count \& platelet count with serum Iron profile suggestive of Iron deficiency anemia.

Renal and Liver functional tests were normal with hypoalbuminemia Thyroid function test were normal, serological findings for HIV, hepatitis B \&C were non- reactive. Routine examination of urine was normal with absent Bence jones protein,24 hour urinary protein was within normal range.

Serum ANA was negative, serumelectrophoresis revealed protein accumulation in the alpha and beta region, diffuse band ingamma region. Stool for occult blood was positive.

Abdominal sonography and CECT-abdomen were suggestive of chronic calcific pancreatitis, mildly enlarge pancreas at head region with tiny calcificationin the pancreatic body region of $1.5-2 \mathrm{~mm}$, irregular pancreatic outline with prominent major pancreatic duct, mild enlarged spleen and minimal collection in both pleural cavity.

Upper GI Endoscopy showed multiple punched out hypertrophied lesion infundus and body region (Fig 2) suggestive of a multiple small polypoidal lesion with gastric erosions.

Histopathological examination of the biopsy sample was suggestive of chronic gastritis with glandular atrophy. On hematoxylin \& Eosin stain (Fig 3) amorphous material in the laminapropria was found exhibiting eosinophilia and was confirmed with Congo red stain (an apple green birefringence on polarizing microscopy) consistent with gastric amyloidosis. 
Rectal biopsy examination and staining with Congo red features were also consistent with amyloidosis. Bone marrow aspiration showed mature bone marrow with decreased iron store. $\mathrm{X}$ ray skull was normal.

2D-Echo revealed features of diastolic dysfunction.

A definitive diagnosis of primary systemic light-chain amyloidosis with gastrointestinal tract involvement was made. The patient was not considered for autologous stem cell transplantation, since the outcomes of autologous stem cell transplant in patients with multisystem involvement are often poor and fraught with a high mortality risk [8].

Fig 1: Patient with features of Primary Systemic Amylodosis :periorbitalpurpura and macroglossia (Photo taken after consent)

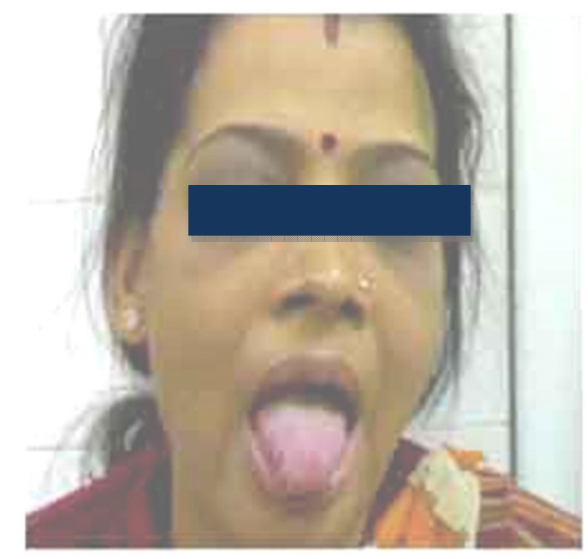

Fig 2:Upper GI endoscopy showing multiple punched out hypertrophied lesions in fundus and body region

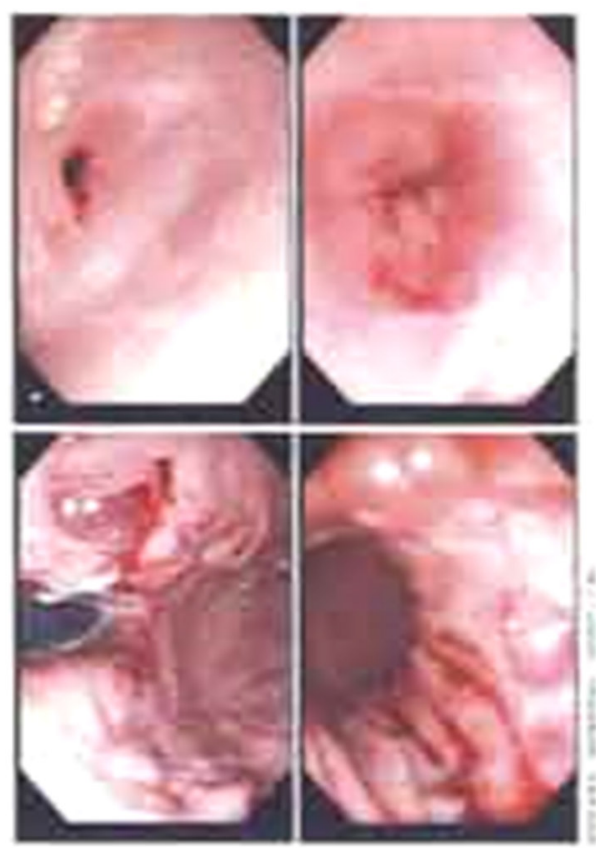

Fig 3: Gastric Amyloidosis (magnification $\times 100$ ) showing eosinophilic deposits stained with Congo Red 


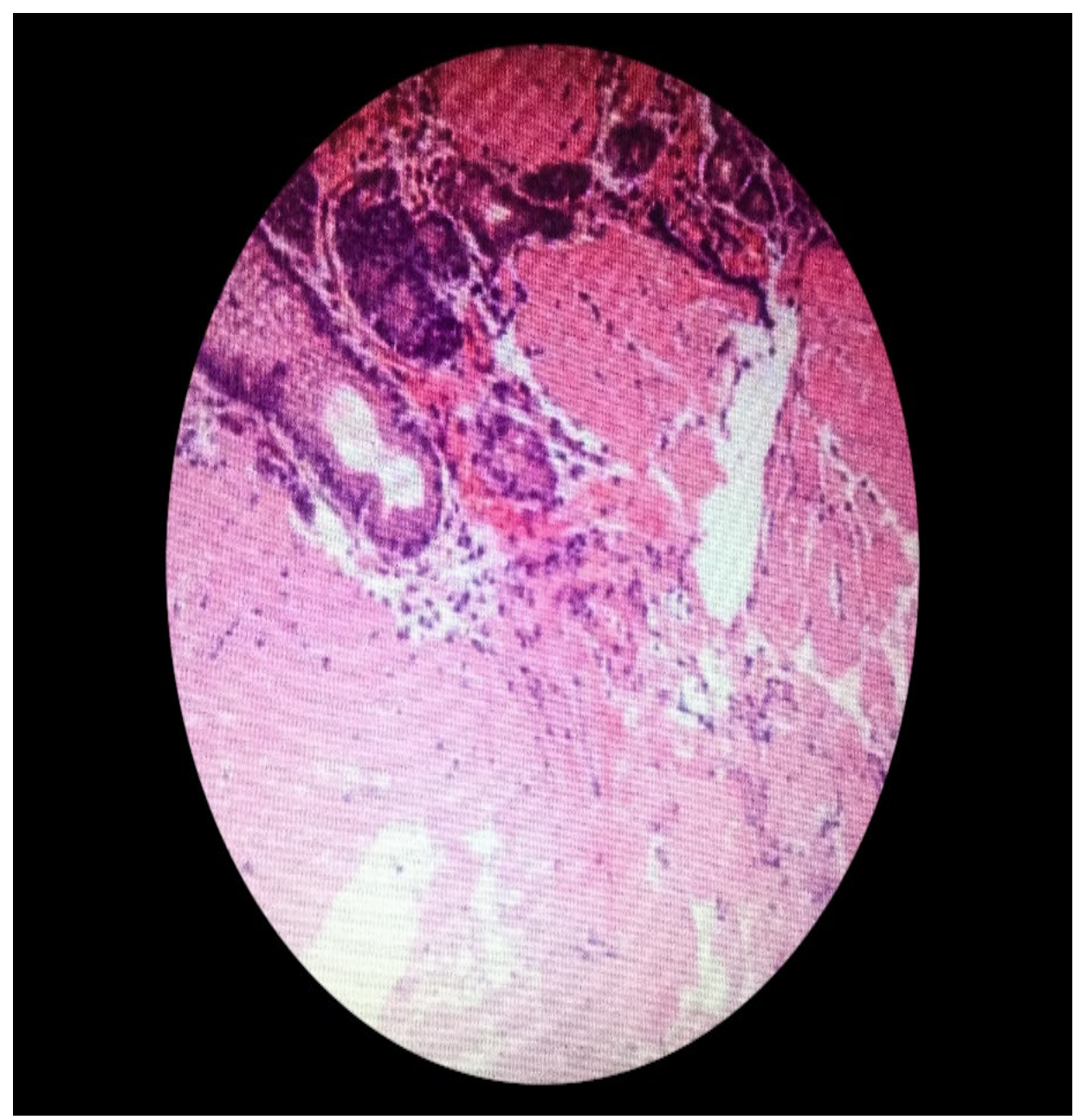

\section{Discussion}

Menke D. $\mathrm{M}$ et al in their study reported that only about 8\% of patients have biopsy-proven amyloidosis in the gastrointestinal tract and only about $1 \%$ become symptomatic from gastric involvement [7] [8].

The gastrointestinal amyloidosis spectrumis wide with presentation of gastroesophageal reflux disease-like symptoms, nausea, abdominal pain and symptoms like diarrhea, weight loss (most common symptom as per Madsen LG et al in their study [9].

Gastrointestinal hemorrhage could be seen in up to $45 \%$ of patients with amyloidosis, likely secondary to ischemia, ulceration or generalized mucosal oozing as per study by Levy DJ et al [10].

Our patientpresented with weight loss, anorexia, anemia due to upper gastrointestinal bleeding, macroglossia, periorbital purpura.

The features were suggestive of primarysystemic amyloidosis and there were evidences of other systemic involvement such ascardiac, spleen and stomach [10] [11]. 
Echocardiography findings were suggestive of restrictive cardiomyopathy, abdominal sonography revealed splenomegaly and upper gastrointestinal endoscopy showed amyloid nodules with erosions.

The underlying pathology for most of these symptoms is amyloid infiltration. In our case there were no clinical or investigational findings suggestive of Multiple Myeloma or Collagen vascular disease.

Amyloidosis was proven by biopsy and laboratory investigations. Computed tomography of abdomen confirmedthe evidence of chronic calcific pancreatitis.

After proper examination and laboratory reports of the patient, conclusion was made that thelady was a case of Symptomatic Gastric amyloidosiswith chronic calcific pancreatitisin setting of primary systemic amyloidosis.

\section{Conclusions}

There are very few cases reported of primary systemic amyloidosis withsymptomatic gastric involvement and few literatures are available of this relationship specially pertaining to involvement of pancreas in the form of chronic calcific pancreatitis. Only few endoscopic findings have been published, but the differential diagnosis should be kept in mind by gastroenterologists.

Abbreviation used:AL-Amyloid light chain, AA-Amyloid A protein, ATTR-Amyloid transthyretin

\section{References}

1. Diseases of immunity. In: Cotran RS, Kumar V, Collins Teds. Robbins Pathologic Basis of Disease. 6th ed. Philadelphia,PA: Saunders, 1999; 251-6.

2. Piscaglia AC, Larocca LM, Cammarota G.Education and imaging. Gastrointestinal: An unusual gastric flat lesion: amyloidosis.J GastroenterolHepatol. 2011 Apr; 26(4):784. doi: 10.1111/j.1440-1746.2011.06616.x.

3. Biswas S, Iqbal J, Makin A.BMJ Case Rep. 2010 Aug 13;2010. pii: bcr0120102650. doi: 10.1136/bcr.01.2010.2650.

4. Niraj A, Perez NE, Sakr-Khoury N, Adsay V, Basturk O, Tobi M et al. Localized gastric amyloidosis. Practical Gastroenterology. 2006; 30(7):73-9.

5. Deniz K, Sari I, Torun E, Patiroğlu TE. Localized gastric amyloidosis: a case report.Turk J Gastroenterol. 2006 Jun;17(2):116-9.

6. Vaideeswar P, Chetty R. Amyloidosis of exocrine pancreas. J Postgrad Med. 2011 Jan-Mar;57(1):61-2. doi: 10.4103/0022-3859.74295. 
7. Menke D. M., Kyle R. A., Fleming C. R., Wolfe J. T, Kurtin P. J., Oldenburg W. A. Symptomatic gastric amyloidosis in patients with primary systemic amyloidosis. Mayo Clinic Proceedings. 1993;68(8):763-767. doi: 10.1016/s00256196(12)60634-x.

8. Gaduputi V, Badipatla K, Patel H, Tariq H, Ihimoyan A. Primary systemic amyloidosis with extensive gastrointestinal involvement.Case Rep Gastroenterol. 2013 Dec 12;7(3):511-5. doi: 10.1159/000357589. eCollection 2013.

9. Madsen LG, Gimsing P, Schiødt FV.Primary (AL) amyloidosis with gastrointestinal involvement.Scand J Gastroenterol. 2009; 44(6):708-11. doi: 10.1080/00365520902783717.

10. Levy DJ, Franklin GO, Rosenthal WS. Gastrointestinal bleeding and amyloidosis. Am J Gastroenterol. 1982;77:422426.

11. Reidar Fossmark, Espen Skarsvåg, Harald Aarset, Henrik Hjorth-Hansen, and Helge L. Waldum Symptomatic Primary (AL) Amyloidosis of the Stomach and Duodenum,Case Reports in Gastrointestinal Medicine 2013; vol2013(Article ID 52543):3 pages http://dx.doi.org/10.1155/2013/525439.

\section{How to cite this article?}

A case report on and chronic calcific pancreatitis primary systemic amyloidosis with symptomatic gastric involvement. Kumar R, Chakraborthy SR, Bandopadhyay A, Pandit VK, Bandi HK. Int J Med Res Rev 2016;4(2):267-272. doi: 10.17511/ijmrr.2016.i02.004. 